\title{
Incidence of vascular complications in patients submitted to percutaneous transluminal coronary angioplasty by transradial and transfemoral arterial approach*
}

\author{
Incidência de complicações vasculares em pacientes submetidos a angioplastia coronariana \\ transluminal percutânea por via arterial transradial e transfemoral
}

Incidencia de complicaciones vasculares en pacientes sometidos a angioplastía coronaria transluminal percutánea por vía arterial transradial y transfemoral

\author{
Marinez Kellermann Armendaris ${ }^{1}$, Karina de Oliveira Azzolin ${ }^{2}$, Fabiane \\ Jaqueline Martins Santos Alves ${ }^{3}$, Simone Giradello Ritter ${ }^{4}$, Maria Antonieta \\ Pereira de Moraes ${ }^{5}$
}

\begin{abstract}
Objective: To describe the vascular complications of transradial and transfemoral artery punctures in patients submitted to percutaneous transluminal coronary angioplasty (PTCA). Methods: Prospective cohort study including patients submitted to PTCA. An interview was performed and an instrument applied to collect risk factors/predictors of complications. After the procedure, a physical examination was performed, vital signs were measured and the puncture site was assessed. Results: 199 patients were included, age $64 \pm 10$ years. Complications found for the radial and femoral approach were respectively: ecchymosis (18.29\%), (17.14\%); bruising (17.66\%), (14.27\%); urinary retention $(2.43 \%),(25.71 \%)$; loss of vessel permeability $(8.53 \%),(0 \%)$. Conclusion: The complications found were considered minor or secondary, depending on the classification found in literature. A higher rate of vascular complications related to transradial artery punctures compared to the interventions performed by transfemoral approach.
\end{abstract}

Keywords: Angioplasty, transluminal; percutaneous coronary/adverse effects; Postoperative complications/nursing

\section{RESUMO}

Objetivo: Descrever as complicações vasculares relacionadas às punções arteriais transradial e transfemoral, em pacientes submetidos à angioplastia coronariana transluminal percutânea (ACTP). Métodos: Estudo de coorte prospectivo que incluiu pacientes submetidos à ACTP. Foi realizada entrevista e aplicado um instrumento para coleta de fatores risco/preditores de complicações. Após o procedimento foi realizado exame físico, mensuração dos sinais vitais e avaliado o local da punção. Resultados: Foram incluídos 199 pacientes, com idade $64 \pm 10$ anos, Complicações encontradas para via radial e femoral respectivamente: equimose (18,29\%), $(17,14 \%)$; hematoma $(17,66 \%)$, $(14,27 \%)$; retenção urinária $(2,43 \%),(25,71 \%)$; perda de permeabilidade do vaso $(8,53 \%),(0 \%)$. Conclusão: As complicações presentes foram consideradas menores ou secundárias conforme classificação literária. Existiu maior incidência de complicações vasculares relacionadas às punções arteriais transradiais quando comparadas às intervenções realizadas pela via transfemural.

Descritores: Angioplastia transluminal percutânea coronária/feitos adversos; Complicações pós-operatórias/enfermagem

\section{RESUMEN}

Objetivo: Describir complicaciones vasculares relacionadas a punciones arteriales transradial y transfemoral en pacientes sometidos a angioplastía coronaria transluminal percutánea (ACTP). Métodos: Se trata de un estudio de cohorte prospectivo realizado con pacientes sometidos a ACTP. Se llevó a cabo una entrevista y aplicó un instrumento para obtener factores de riesgo/predictores. Fue realizado un examen físico, medición de signos vitales y se evaluó el lugar de punción. Resultados: Fueron incluidos 199 pacientes, edad $64 \pm 10$ años. Las complicaciones encontradas para vía radial y femoral respectivamente, fueron: esquimosis (18,29\%), (17,14\%); hematoma (17,66\%), $(14,27 \%)$; retención urinaria $(2,43 \%),(25,71 \%)$; pérdida de permeabilidad de vaso $(8,53 \%),(0 \%)$. Conclusión: Las complicaciones fueron consideradas menores o secundarias conforme clasificación literaria. Existe una mayor incidencia de complicaciones vasculares relacionadas a punciones arteriales transradiales que cuando las intervenciones se realizan por vía transfemoral.

Descriptores: Angioplastía transluminal percutánea coronaria/efectos adversos; Complicaciones postoperatorias/enfermería

\footnotetext{
* Monograph presented to obtain the Title of Spcielist in Cardiology in the Nurisng in Cardiology Postgraduation Cousre of the Fundação Universitária de Cardiologia - FUC - Porto Alegre (RS), Brazil

${ }^{1}$ Cardiology Nursing Graduate Student of the Postgraduation Program of the Fundação Universitária de Cardiologia - FUC - Porto Alegre (RS), Brazil. ${ }^{2} M S c$, Professor of the Porto Alegre Methodotist Institute; Faculty member of the Postgraduation Program of the Fundação Universitária de Cardiologia FUC - Porto Alegre (RS), Brazil.

3 Specialist in Intensive Therapy, Faculty member of the Nursing Course of the Universidade de Passo Fundo (RS), Brazil.

${ }^{4}$ RN, Hospital São Vicente de Paulo, Specialist in Health Auditing; Faculty memebr of the technical Course in Radiology of the Universidade de Passo Fundo. Passo Fundo ( RS), Brazil.

${ }^{5}$ MSc, Professor of the Cardiology Nursing Postgraduation Programof the Fundação Universitária de Cardiologia - FUC - Porto Alegre (RS), Brazil.
} 


\section{INTRODUCTION}

The expansion of devices in interventionist cardiology has provided multiple treatment options for patients with coronary artery disease (DAC). Percutaneous interventions have increased due to advanced technology, minimal invasion, increased success rates and fewer complications ${ }^{(1)}$.

Femoral arterial access is usually the way of choice, providing better speed and repeatability, easy localization due to larger vessel caliber, material variability, and it demands little experience from the operator. However, it is necessary for the patient to be restrained to the bed, leading to some discomfort and demanding a minimum hospital stay ${ }^{(2)}$. Due to technological advances, availability of new materials and professional improvement, it was necessary to develop arterial alternatives, such as transradial, brachial and ulnar approaches. A study performed in 103 patients submitted to coronary intervention by radial approach was successful in $94 \%$ of the patients, with $1 \%$ of vascular complications, making it evident that the radial artery is rated positively as a way of $\operatorname{access}^{(3)}$.

The ACCESS reference study, published in 1997, compared the transradial, transfemoral and brachial approaches in 900 patients submitted to coronary angioplasty, successful in $91.7 \%, 90.7 \%$ and $90.7 \%$, respectively, with no hemorrhagic effect identified for the radial technique, whereas this complication was observed in $2.3 \%$ and $2.0 \%$ of the patients submitted to brachial and femoral techniques, respectively ${ }^{(4)}$.

Transradial access is a safe alternative, offering more comfort to the patient regarding mobility, early ambulation, lower hospital costs, presenting similar or even lower complication rates when compared to femoral arterial approach ${ }^{(5)}$.

Although vascular complications are not very frequent, these are usually related to calcification in the punctured artery, obesity, age, sex, hypertension and use of anticoagulants. The highest incidence happens at the puncture site, in the form of hemorrhages, bleedings, bruises, fistulas, pseudo-aneurysms and ischemia ${ }^{(6-7)}$. Early interventions by the nurse, identifying and assessing possible vascular complications may minimize its effects, reducing the patient's discomfort, aiding in the reduction of hospital expenses and contributing for an effective assistance, consolidating the integrality of healthcare.

In face of the factors above, the present study intended to describe the vascular complications related to transradial and transfemoral arterial punctures in patients submitted to percutaneous transluminal coronary angioplasty (ACTP).

\section{METHODS}

This was a prospective cohort study, performed from March to May/2006, in a Cardiology reference hospital in the state of Rio Grande do Sul.

Patients of both sexes were included, with age $\geq 18$ years, submitted to ACTP via radial and femoral arteries. Patients with grave associated comorbidities, such as uncompensated congestive cardiac insufficiency, neoplastics or chronic kidney insufficiency were excluded.

Patients were submitted to individual interviews by the researcher shortly after admission, where a structured instrument was applied to collect clinical and demographic data, medication being used and associated comorbidities that could indicate possible predictive complicating factors.

Patients who were about to undergo the procedure via radial artery were submitted to the Allen Test beforehand, in order to verify radial/ulnar arterial perfusion. After the procedure, the valved introducer was removed and manual compression was performed with a compressive bandage placed on the puncture site. In the patients submitted to femoral puncture, the compression was mechanical, by means of a $5-\mathrm{Kg}$ metal weight for no less than 15 minutes, and after that, the weight was replaced by a $2-\mathrm{Kg}$ sandbag, for no longer than 2 hours. In the whole sample studied, the 6-French valved introducer was used, and the full heparin dose was 10,000 units. After the end of the procedure, a physical exam was performed in all patients, with the following vital signs being measured: arterial pressure, heart rate, respiratory rate and body temperature. The puncture site wad evaluated until the patient's discharge from hospital for the presence of vascular complications.

According to Standars studies, minor complications were determined: ecchymosis, bruises, urinary retention and loss of vessel permeability. Major complications: aneurysms, pseudo-aneurysms and hemorrhages needing blood transfusion.

Bruises were classified as large: palpable mass $>8$ $\mathrm{cm}$, medium $\mathrm{e} \geq 2$ to $8 \mathrm{~cm}$ and small $<2 \mathrm{~cm}$.

Pain in the puncture site was evaluated as the $5^{\text {th }}$ vital sign, observing its intensity with the linear pain scale for further comparison between the groups: $0=$ absence of pain, 1-3 = low intensity pain, 4-6 = moderate intensity pain, $7-9=$ high intensity pain and $10=$ extreme intensity pain.

The project was approved by the Review Board of the institution, where all the participants agreed to take part in the study.

The continuous variables were described as the average \pm standard deviation, and the categorical 
variables through the Tables of absolute and relative frequencies. To compare the categorical variables among the groups, the Chi-square and Student's t tests were used, with $\mathrm{P} \leq 0.05$ considered significant.

\section{RESULTS}

The 199 studied patients were $64.69 \pm 10$ years old, and predominantly male. Successful procedures occurred in $98 \%$ of the sample submitted to radial approach angioplasty and $100 \%$ by femoral approach. Emergency procedures were performed in 3\% of patients. The coronaries most often struck and treated were the anterior descending artery in $47 \%$ of the patients, followed by the right coronary artery in $27 \%$ and circumflex coronary in $26 \%$.

Initial diagnosis was one of ischemic etiology, in which the patients admitted with angina were prevalent $(95.97 \%)$. Comorbidities most often associated to coronary artery disease were systemic arterial hypertension and diabetes mellitus. Most of the population was overweight, with body mass index $>$ $25 \mathrm{Kg} / \mathrm{m}^{2}$ (Table 1).

\section{Vascular complications related to arterial ways of choice}

When vascular complications related to transradial and transfemoral arterial punctures are analyzed, all of them were considered minor or secondary, according to literary classification. It can be observed in Table \#2 that ecchymosis and bruises were predominant, related to the radial arterial access when compared to the femoral arterial approach. The most prevalent complication for the femoral approach was urinary retention $(\mathrm{P}=0.001)$. Loss of vessel permeability happened exclusively in radial approach procedures, with a significant statistical difference $(\mathrm{P}=0.001)$ between both approaches.

Table 1 - Clinical and demographic characteristics of the population

\begin{tabular}{lccc}
\hline Caractheristics & $\begin{array}{c}\text { Radial approach } \\
\mathbf{n}=\mathbf{1 6 4}\end{array}$ & $\begin{array}{c}\text { Femoral approach } \\
\mathbf{n}=\mathbf{3 5}\end{array}$ & $\mathbf{p}$ \\
\hline Age (years) & $64,12 \pm 9,89$ & $67 \pm 10,22$ & 0,670 \\
Males & $122(74,39 \%)$ & $18(51,43 \%)$ & 0,080 \\
BMI $\left(\mathrm{Kg} / \mathrm{m}^{2}\right)$ & $26,86 \pm 4,12$ & $25,46 \pm 3,62$ & 0,430 \\
Comorbidities & & & \\
HAS & $138(84,15 \%)$ & $27(77,14 \%)$ & 0,220 \\
IAM & $6(3,65 \%)$ & $0(0 \%)$ & 0,001 \\
DVP & $3(1,83 \%)$ & $2(5,71 \%)$ & 0,210 \\
DM & $45(27,60 \%)$ & $4(11,42 \%)$ & 0,050 \\
Gastritis & $8(4,87 \%)$ & $4(11,42 \%)$ & 0,230 \\
Previous percutaneous intervention & $84(51,21 \%)$ & $24(68,57 \%)$ & 0,610 \\
Medication & & & \\
Anti-platelet (previously) & $134(8,70 \%)$ & $26(74,28 \%)$ & 0,310 \\
Anti-Hypertensive & $113(68,90 \%)$ & $26(74,28 \%)$ & 0,140 \\
Diuretic & $25(15,24 \%)$ & $2(5,71 \%)$ & 0,130 \\
Anti-platelet (after) & $98(59,75 \%)$ & $25(71,42 \%)$ & 0,030 \\
Inhibitor glucoprotein IIb IIIa & $1(0,61 \%)$ & $3(8,57 \%)$ & 0,540 \\
Non-fractionated Heparin & $135(82,32 \%)$ & $15(42,86 \%)$ & 0,001 \\
PAS (introductor removed) & $143,34 \pm 26,05$ & $129,71 \pm 19062$ & 0,090 \\
PAD (introductor removed) & $84,44 \pm 12,95$ & $78,57 \pm 11,11$ & 0,230 \\
\hline Continuous variables expressed as mean \pm standard deviation and categorical variables expressed as $\%$. \\
Descriptions: BMI: Body Mass Index, SH: Systolic Hypertension, PVD: Peripheral Vascular Disease, DM: \\
Diabetes Mellitus, SBP: Systolic Blood Pressure, and DBP: Diastolic Blood Pressure. &
\end{tabular}

Table 2 - Complications related to arterial vias of choice

\begin{tabular}{lccc}
\hline Complications & $\begin{array}{c}\text { Radial approach } \\
\mathbf{n = 1 6 4}\end{array}$ & $\begin{array}{c}\text { Femoral approach } \\
\mathbf{n}=\mathbf{3 5}\end{array}$ & $\mathbf{p}$ \\
\hline Presence of local ecchymosis & $30(18,29 \%)$ & $6(17,14 \%)$ & 0,540 \\
Presence of small bruise & $9(5,48 \%)$ & $1(2,85 \%)$ & 0,790 \\
Presence of medium-size bruise & $14(8,53 \%)$ & $2(5,71 \%)$ & 0,780 \\
Presence of large bruise & $6(3,65 \%)$ & $2(5,71 \%)$ & 0,880 \\
Presence of urinary retention & $4(2,43 \%)$ & $9(25,71 \%)$ & 0,001 \\
$*$ Loss of vessel permeability & $14(8,53 \%)$ & $0(0 \%)$ & 0,001 \\
\hline Continuous variables: average \pm standard deviation and categorical variables: percentiles $(\%)$. Small bruise: $<$ \\
$2 \mathrm{~cm}$. Medium sized bruise: $2-8 \mathrm{~cm}$; large bruise: palpable mass $>8 \mathrm{~cm}$. ${ }^{*}$ reduction or occlusion of the blood \\
flow in the punctured artery site.
\end{tabular}




\section{Linear pain scale on the puncture site after ACTP}

The pain reported by the patients on the arterial puncture site was assessed immediately after ACTP, using parameters described in the bibliography through a linear pain scale. The findings showed that $38 \%$ of the patients mentioned moderate pain when the procedures were performed by femoral approach versus $35 \%$ of the patients mentioning low-intensity pain when performed by radial approach.

\section{Risk factors / complication predictors}

Our results made evident a significant statistical difference regarding the presence of arterial hypertension among the groups, $37(90.24 \%)$ versus $8(61.51 \%)$ for radial and femoral approaches, respectively $(\mathrm{P}=0.03)$. A higher incidence of complications was observed among female patients.

\section{DISCUSSION}

Diversity in arterial ways is shown to be effective to perform interventionist cardiology procedures, not only in Brazil. A study ${ }^{(7)}$ performed in the USA reports that two institutions executed 2,500 diagnostic exams and 1,100 interventions in a year, with $85 \%$ of the procedures being performed by femoral approach, $10 \%$ by radial approach and $5 \%$ by brachial approach.

The present study showed that the radial approach was prevalent in $82.41 \%$ of the coronary interventions, with a success rate of $98 \%$. These data corroborate with other studies that show increased usage of the radial approach for coronary interventions ${ }^{(2,7)}$. Currently, the incidence of minor vascular complications, related to arterial access, such as bruises, are described in literature as being between $0.1 \%$ and $9 \%{ }^{(8)}$.

In this population-based cohort study, the results showed complications such as ecchymosis in (18.29\%) and small, medium and large bruises $(17.66 \%)$ in higher frequencies for the radial approach $(17.14 \%)$ and $(14.27 \%)$ for the femoral approach. These findings can be related to a high rotation of professionals executing the technique, since the setting is a university hospital. They can also be attributed to the use of bandages (adhesives without elasticity) as a mechanic compression and the absence of routine controls of active coagulation time. Such factors diverge from those found in a recent study performed in Italy, conducted by nurses, showing bruising complication rates after ACTP in 10\% of the radial approach interventions and $16.5 \%$ of the femoral approach interventions, related to the use of glucoproteins IIb IIIa and active coagulation time superior to 250 seconds $^{(7)}$. These findings show that vascular complications are present in both approaches.

By analyzing only urinary retention as a post- procedure complication, a significant difference can be seen between both approaches $(P=0.001)$. In the femoral approach procedures, it was evident that a urinary catheterization was necessary in $25.71 \%$ of the patients, since they did not respond to the usual noninvasive measures of spontaneous diuresis. When the radial approach is used, only $2.43 \%$ of the patients presented urinary retention. However, in this group, such complication was solved when they were released to move in the bed and to ambulate early to the bathroom. In the randomized study performed by Augustin et $\mathrm{al}^{(9)}$, it was shown that the urinary retention rate requiring catheterization in patients submitted to ACTP via femoral approach represented $2 \%$ versus $7 \%$ for patients where early ambulation and non-invasive measurements were used. This reinforces the notion that the patient's comfort, reduced hospital stays and its additional costs represent higher benefits when the via of choice is the radial approach ${ }^{(3,10)}$.

Loss of vessel permeability occurred in $8.53 \%$ when the radial approach was used, showing a statistical significance between the groups $(\mathrm{P}=0.001)$. This complication, although not having higher clinical repercussions, seems to be a limiting factor in the usage of the radial artery. The authors' experience suggests that the time of mechanical compression may be related to these findings. Studies ${ }^{(6,8)}$ describe occlusion rates from $5 \%$ to $25 \%$ in the radial artery after these procedures, not representing important clinical alterations when the Allen Test is adequately performed.

Although it is not usual to investigate the intensity of pain reported by the patients in the puncture site after the intervention in the base studies, it is relevant to mention these findings, since they are commonly mentioned by the patients, as well as concerns about the clients' welfare. These results make evident that, according to the linear scale of pain, $38 \%$ of the patients mentioned moderate intensity pain when the procedures were performed by femoral approach versus 35\% mentioning low intensity pain when performed by radial approach. Although subjective, pain can be a distressing experience, and controlling it may minimize the inpatients' discomfort and anxiety ${ }^{(10)}$.

As for the risk factors/complication predictors present in the population, the study demonstrated that there was a higher incidence of complications in overweight (BMI > 25) female patients, tending to arterial hypertension, which may have contributed to these results. These findings are in harmony with those published by Anderson et $\mathrm{al}^{(11)}$, relating female gender and systolic arterial pressure $>160 \mathrm{mmHg}$ with the formation of bruises. The results of this study bring important data about the reality of the service and point to a population with high incidence of vascular complications, when 
compared to current journals, suggesting the need of revision of the processes related to assisting the patient submitted to ACTP.

\section{CONCLUSION}

Successful procedures occurred in $98 \%$ of the sample submitted to radial approach and $100 \%$ for interventions performed via femoral approach. The results showed that the complications presented were considered minor or secondary, according to literary classification. Higher incidence of vascular complications related to transradial arterial punctures when compared to interventions performed via transfemoral approach.

Early identification of possible predictors of complications was observed to represent an important factor in the choice of arterial approach. The findings

\section{REFERENCES}

1. Woods SL, Froelicher ESS, Motzer SA. Enfermagem em Cardiologia. 4a. ed. Barueri, SP: Manole; 2005. p.629-50.

2. Roebuck A, Jessop S, Turner R, Caplin JL. The safety of two-hour versus four-hour bed rest after elective 6-French femoral cardiac catheterization. Coronary Health Care. 2000; 4(4):169-173.

3. Kiemeneij F, Laarman GJ, Odekerken D, Slagboom T, van der Wieken R. A randomized comparison of percutaneous transluminal coronary angioplasty by the radial, brachial and femoral approaches: the access study. J Am Coll Cardiol. 1997; 29(6):1269-75.

4. Amoroso G, Sarti M, Bellucci R, Puma FL, D'Alessandro $\mathrm{S}$, Limbrumo U, et al. Clinical and procedural of predictors of nurse workload during and after invasive coronary procedures: the potential benefit of a systematic radial access. Eur J Cardiovasc Nurs. 2005; 4(3):234-41.

5. Safian RD, Freed M. The manual of interventional cardiology. 3a ed. Birmingham, Michigan: Physicians' Press; 2001.

6. Steffenino G, Dutto S, Conte L, Dutto M, Lice G, Tomatis $\mathrm{M}$, et al. Vascular access complications after cardiac of this study contribute for the quantification of complications in this service, reinforcing the need of elaborating goals to reduce such effects, as well as the development of protocols of assistance. It is necessary that the teams of interventionist cardiology professionals discuss and reevaluate the arterial way of choice, according to the presence of risk factors or predictors of complications, minimizing complications.

Some limitations in this study were considered, such as the absence of routine verifications of the active coagulation time after interventions, and a follow-up of the patients after being discharged from the hospital, in order to know about possible complications, which would make it possible to have better control of the patients' evolution after coronary intervention. The development of new studies is fundamental to seek out more evidence about the identified problems.

catheterisation: a nurse-led quality assurance program. Eur J Cardiovasc Nurs. 2006; 5(1):31-6. Comment in: Eur J Cardiovasc Nurs. 2006; 5(1):3-4.

7. Andersen K, Bregendahl M, Kaestel H, Skriver M, Ravkilde J. Haematoma after coronary angiography and percutaneous coronary intervention via the femoral artery frequency and risk factors. Eur J Cardiovasc Nurs. 2005; 4(2):123-7.

8. Souza AGMR, Staico R, Souza JEMR. Stent Coronário: aplicações clínicas. São Paulo: Atheneu; 2001.

9. Augustin AC, Quadros AS, Yordi LM, Sarmento Leite R. Retenção urinária e seu manejo após intervenções coronarianas percutâneas. In: XXVIII Congresso da SBHCI e XII Congresso SOLACI, 2006, Recife. Rev Bras Cardiol Invasiva. 2006; 14(2): 247.

10. Dal Molin RS. Cuidando da dor na perspectiva da Enfermagem. Goiânia: AB; 2004.

11. Andersen K, Bregendahl M, Kaestel H, Skriver M, Ravkilde J. Haematoma after xoronary angiography and percutâneos coronary intervention via the femural artery frequency and risk factors. Eur J Cardiovasc Nurs. 2005; 4(2):123-27. 